\title{
Physical Development of Modern Schoolchildren of the Republic of Sakha (Yakutia)
}

\author{
Lena A. Stepanova ${ }^{1,}$, Sargylana Yu. Artamonova ${ }^{1}$, Maria V. Handy ${ }^{1}$, Sardana V. \\ Markova $^{1}$ and Nadezhda M. Zakharova ${ }^{1}$
}

\begin{abstract}
${ }^{1}$ North-Eastern Federal University named after M.K. Ammosov, Medical Institute, 27, Oyunsky St., 677000, Yakutsk, Russia

${ }^{*}$ Corresponding author. Email: la.stepanova@s-vfu.ru
\end{abstract}

\begin{abstract}
The state of health of children is one of the indicators of the quality of the environment, social well-being and the level of health of the country. The purpose of this study was to assess the physical development of children and adolescents. To assess the physical development of children and adolescents living in Yakutsk and the central regions of the Republic of Sakha (Yakutia). 1,305 children aged 8-15 years old were examined. Physical development was investigated using anthropometry and handgrip test according to generally accepted methods. The following results were obtained: according to anthropometry, modern schoolchildren have secondary physical development. According to our data 11, 12-year-old girls are higher than boys of the same age, and from the age of 14 the body length of boys exceeds the body length of girls. Body weight indicators do not have reliable differences in gender, however, at the age of 13, the body weight of Russian boys is significantly more than the body weight of Yakut boys. Russian girls have higher power opportunities in all age categories than Yakut girls. The power capabilities of Russian boys of prepubertal age belong to high values of physical development. The level of dynamometry in all age categories belongs to the $90-$ centile corridor, which indicates high physical development in girls of Russian nationality. For girls of Yakut nationality, only at the age of 10 and 12, power capabilities are higher than average values. Thus, children of Russian nationality living in the Republic of Sakha (Yakutia), functional indicators (handgrip test) exceed average values.
\end{abstract}

Keywords: physical development, schoolchildren, social well-being, population health, Republic of Sakha (Yakutia)

\section{INTRODUCTION}

The physical development of children and adolescents is one of the informative indicators of the levels of assessment of public health. Simplicity and accessibility of anthropometric measurements among children, information of obtained data give physical development along with morbidity indicators and medical and demographic data the objective criterion of sanitary and hygienic well-being of population [1-4]. It is also known that the physical development of children is closely related to cognitive, emotional and social development and is one of the indicators of the social well-being of the population [3, 4]. Negative factors affecting the intrauterine period and in early childhood can disrupt the sequence of growth and development of the body, in some cases causing irreversible changes [4]. Environmental factors - the conditions of nutrition, upbringing, the presence of diseases, social and other factors during the period of intensive growth and development of a child can have a great influence on the characteristics of physical development $[5,6]$. The share of inherited and acquired physical development in programming has been the subject of discussion over the past few decades. The variability of the share of inherited factors in the determinants of an individual's final growth is $45-85 \%$, and this share is largely determined by the evaluation method and is associated, in particular, with race and ethnicity [7]. 
Modern living and nutritional conditions lead children and adolescents to increase their body weight [5-7]. In this regard, obesity trends among children and adolescents should be monitored [8]. Functional indices, in particular muscle strength, reflect state of muscular and nervous system of child and is integral indicator of training and endurance [9]. The success of adapting children and adolescents to the conditions of modern life will determine to a decisive extent the future reproductive and labor potential of the country, its development and the level of national security.

The purpose of the research is to assess the physical development of modern schoolchildren living in the Republic of Sakha (Yakutia). The Republic of Sakha (Yakutia) is located in the north-eastern part of the Eurasian continent, is part of the Far Eastern Federal District and is the largest region of the Russian Federation. The total area of the continental and insular (Lyakhovsky, Anjou and De Long, which are part of the Novosibirsk Islands of the Arctic Ocean) territory of Yakutia is 3.1 million square kilometers. The climate of the Republic of Sakha (Yakutia) is among continental and extreme, where the maximum amplitude of the average temperature of the coldest month is January and the warmest - July is $70-75{ }^{\circ} \mathrm{C}$. According to the characteristics, Yakutia has no analogues in the Northern hemisphere.

\section{METHODS AND MATERIALS}

To assess the physical development of children and adolescents living in Yakutsk and the central regions of the Republic of Sakha (Yakutia), 1,305 children aged 8-15 years were examined: the 1st group - Yakut boys (415 children); the 2nd group - Yakut girls (425 children); the 3rd group - Russian boys (227 children); the 4 th group - Russian girls ( 238 children). As part of mass preventive examinations, there was a longitudinalmixed observation of the physical development of students of secondary schools in Yakutsk and rural areas. The observation program consisted of anthropometry of the leading signs of physical development - length $(\mathrm{cm})$, body weight $(\mathrm{kg})$, a study of muscle strength of the hand $(\mathrm{kg})$. Body length is a constant indicator of physical development. Body weight is a labile indicator of physical development. Dynamometry allows you to assess the level of physical fitness of a person, muscle functionality and the degree of muscle development. The level of physical development was determined by centile tables for body length, body weight and muscle strength. The following levels of physical development were identified: average (average physical development; 25-75 centiles), below average $(25-10 \mathrm{c}$ ), low (below $10 \mathrm{c}$ ), above average (75-90 c), high (above 90 c).

Mean arithmetic values (M), errors of mean ( $\mathrm{t}$ ), mean quadratic deviations (a), smallest and largest values (min and max) of major anthropometric and functional parameters were calculated. Statistical processing was performed by the statistical analysis package "SPSS". The reliability of the differences was proved by the Student's t-criterion.

\section{RESULTS AND DISCUSSION}

Our study found out that between the ages of 8 and 10 , the body lengths of boys and girls were the same. From 11 to 12 years old, girls were ahead of boys. At 13 years old, the body length of boys and girls is compared and from 14 years old boys were ahead of girls (Table 1). The body length of boys was significantly higher than that of 14 years old girls (Yakuts) and 15 years old (Russians, Yakuts) $(p<0.05)$. Comparison of body length on a national basis revealed no reliable differences.

Table 1. Body length indicators of schoolchildren of the Republic of Sakha (Yakutia)

\begin{tabular}{|c|c|c|c|}
\hline Age & Nationality & Boys M (cm) $\pm m$ & Girls $\mathrm{M}(\mathrm{CM}) \pm \mathrm{m}$ \\
\hline \multirow[t]{2}{*}{8} & Yakut & $127.22 \pm 0.74$ & $126.38 \pm 0.98$ \\
\hline & Russian & $131.46 \pm 1.32$ & $129.71 \pm 1.09$ \\
\hline \multirow[t]{2}{*}{9} & Yakut & $132.11 \pm 0.95$ & $130.86 \pm 0.83$ \\
\hline & Russian & $134.37 \pm 0.91$ & $134.04 \pm 0.96$ \\
\hline \multirow[t]{2}{*}{10} & Yakut & $137.76 \pm 1.19$ & $138.87 \pm 1.22$ \\
\hline & Russian & $138.42 \pm 1.01$ & $140.93 \pm 1.44$ \\
\hline \multirow[t]{2}{*}{11} & Yakut & $139.96 \pm 3.42$ & $145.45 \pm 1.26$ \\
\hline & Russian & $147.73 \pm 2.75$ & $146.63 \pm 1.58$ \\
\hline \multirow[t]{2}{*}{12} & Yakut & $150.84 \pm 1.01$ & $152.27 \pm 1.22$ \\
\hline & Russian & $151.33 \pm 1.29$ & $154.01 \pm 1.72$ \\
\hline \multirow[t]{2}{*}{13} & Yakut & $154.74 \pm 1.78$ & $154.83 \pm 0.89$ \\
\hline & Russian & $159.58 \pm 1.76$ & $159.75 \pm 1.51$ \\
\hline \multirow[t]{2}{*}{14} & Yakut & $162.91 \pm 1.43^{* *}$ & $158.03 \pm 0.86^{\star *}$ \\
\hline & Russian & $165.08 \pm 1.39$ & $162.13 \pm 0.92$ \\
\hline \multirow[t]{2}{*}{15} & Yakut & $166.78 \pm 0.85^{\star *}$ & $159.02 \pm 0.75^{\star \star}$ \\
\hline & Russian & $167.80 \pm 1.28^{* *}$ & $161.25 \pm 1.59^{\star \star}$ \\
\hline
\end{tabular}

Body weight indicators did not have reliable differences by gender. At the age of 13, boys of Russian nationality had a reliably large body weight compared to boys of indigenous nationality ( $p<0.05$ ), and boys of Yakut nationality had a body weight less than girls of the same age (Table 2).

According to the centile tables [10.11], the massgrowth indicators of the examined children and adolescents were in the average values of physical development (25-75 centile corridor).

Indicators of physical development are closely related to functional, in particular, power capabilities of a growing organism and cramped this connection changes with age [7]. To determine the functional capabilities of schoolchildren, we used handgrip test. 
Table 2. Body weight indicators of schoolchildren of the Republic of Sakha (Yakutia)

\begin{tabular}{|l|l|l|l|}
\hline Age & Nationality & Boys M (cm) \pm m & Girls M (cm) $\pm m$ \\
\hline 8 & Yakut & $26.99 \pm 0.67$ & $26.81 \pm 1.02$ \\
\cline { 2 - 4 } & Russian & $30.35 \pm 1.68$ & $27.64 \pm 1.13$ \\
\hline \multirow{3}{*}{10} & Yakut & $29.99 \pm 0.90$ & $28.38 \pm 0.93$ \\
\cline { 2 - 4 } & Russian & $32.83 \pm 1.88$ & $29.66 \pm 1.00$ \\
\hline \multirow{3}{*}{11} & Yakut & $36.14 \pm 1.63$ & $36.16 \pm 1.46$ \\
\cline { 2 - 4 } & Russian & $34.88 \pm 1.37$ & $34.67 \pm 1.55$ \\
\cline { 2 - 4 } & Rusut & $40.49 \pm 1.90$ & $39.72 \pm 1.90$ \\
\hline 12 & Yakut & $39.73 \pm 2.60$ & $38.30 \pm 1.97$ \\
\cline { 2 - 4 } & Russian & $46.07 \pm 2.86 \pm 1.71$ & $44.70 \pm 1.74$ \\
\hline 13 & Yakut & $44.91 \pm 1.57^{* *}$ & $47.67 \pm 3.38$ \\
\cline { 2 - 4 } & Russian & $51.94 \pm 2.30^{* *}$ & $48.88 \pm 2.45$ \\
\hline 14 & Yakut & $54.69 \pm 2.19$ & $50.71 \pm 1.66$ \\
\cline { 2 - 4 } & Russian & $55.10 \pm 2.22$ & $51.69 \pm 1.76$ \\
\hline 15 & Yakut & $54.99 \pm 1.35$ & $53.25 \pm 1.40$ \\
\cline { 2 - 4 } & Russian & $57.31 \pm 1.57$ & $53.78 \pm 1.76$ \\
\hline \multirow{2}{*}{$* *-p<0.05$} & &
\end{tabular}

After processing the data, we obtained results that the average values of the hand compression force in boys in all age groups exceed the compression force in girls (Tables 3 and 4). Starting from the age of eight, there are reliable differences in hand strength between students of Yakut and Russian nationality - girls and boys have more left hand dynamometry indicators in children of Russian nationality. At the age of nine, schoolchildren of Russian nationality have dynamometry indicators of the right and left hands higher than that of children of Yakut nationality $(\mathrm{p}<0.05)$. At the age of ten, this indicator is higher only in boys $(\mathrm{p}<0.05)$. At eleven, the force of hand compression in girls of Yakut nationality is less than in Russian girls $(p<0.05)$. In twelve years, this indicator has a reliable difference only in boys with the compression force of the left hand (the indicator is higher in Russian boys) ( $p<0.05)$. At thirteen, the compression force of both hands is higher in Russian boys ( $p<0.05$ ). At fourteen years old, these indicators are higher in Russian girls ( $\mathrm{p}<$ 0.05). At fifteen, both boys and girls have more dynamometry indicators in Russians $(\mathrm{p}<0.05)$.

According to many publications in modern adolescents, functionality is reduced. The percentage of obese children and adolescents is increasing [12, 13]. This is largely associated with a lifestyle: lack of interest in active sports and tourism, nutrition, interests to all kinds of entertainment, the range of which has now expanded significantly. Compared to students of the $60 \mathrm{~s}$, 80 s of the last century, according to some authors, the power capabilities of modern schoolchildren are lower $[14,15]$. However, based on the data we have obtained, the functionality of schoolchildren living in the territory of Yakutia remains at an average and high level.

Table 3. Dynamometry indicators for schoolchildrenboys of the Republic of Sakha (Yakutia)

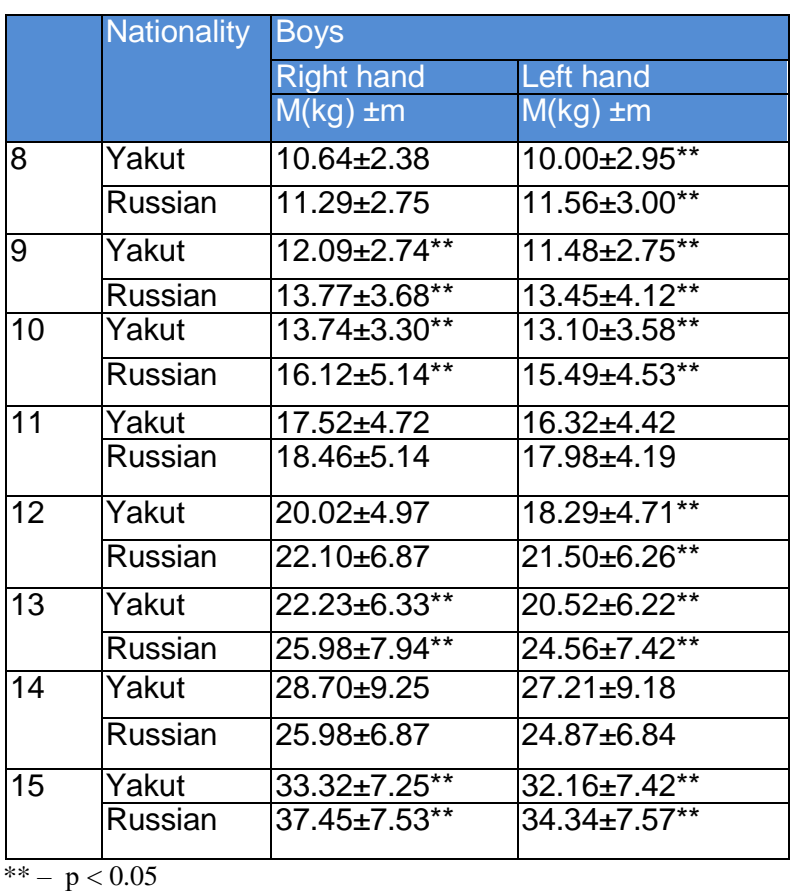

Table 4. Dynamometry indicators for schoolchildrengirls of the Republic of Sakha (Yakutia)

\begin{tabular}{|c|c|c|c|}
\hline \multirow[t]{3}{*}{ Age } & \multirow[t]{3}{*}{ Nationality } & \multicolumn{2}{|l|}{ Girls } \\
\hline & & $\overline{\text { Right hand }}$ & Left hand \\
\hline & & $M(k g) \pm m$ & $M(k g) \pm m$ \\
\hline \multirow[t]{2}{*}{8} & Yakut & $9.94 \pm 2.58$ & $8.99 \pm 2.35^{\star *}$ \\
\hline & Russian & $10.13 \pm 2.69$ & $10.14 \pm 2.60^{\star *}$ \\
\hline \multirow[t]{2}{*}{9} & Yakut & $10.88 \pm 2.74^{\star \star}$ & $10.13 \pm 2.40^{\star \star}$ \\
\hline & Russian & $12.09 \pm 3.19^{* *}$ & $11.50 \pm 2.94^{\star *}$ \\
\hline \multirow[t]{2}{*}{10} & Yakut & $13.18 \pm 3.05$ & $12.35 \pm 3.24$ \\
\hline & Russian & $13.48 \pm 3.14$ & $13.25 \pm 3.14$ \\
\hline \multirow[t]{2}{*}{11} & Yakut & $15.78 \pm 4.43^{\star \star}$ & $14.29 \pm 3.76^{\star *}$ \\
\hline & Russian & $17.89 \pm 5.21^{\star *}$ & $16.23 \pm 4.95^{\star \star}$ \\
\hline \multirow[t]{2}{*}{12} & Yakut & $17.97 \pm 4.59$ & $16.44 \pm 4.37$ \\
\hline & Russian & $19.66 \pm 5.89$ & $17.75 \pm 6.35$ \\
\hline \multirow[t]{2}{*}{13} & Yakut & $20.17 \pm 5.37$ & $18.91 \pm 5.45$ \\
\hline & Russian & $23.53 \pm 11.25$ & $20.77 \pm 6.17$ \\
\hline \multirow[t]{2}{*}{14} & Yakut & $21.15 \pm 5.59^{\star \star}$ & $19.74 \pm 5.45^{\star \star}$ \\
\hline & Russian & $24.73 \pm 12.26^{\star *}$ & $22.17 \pm 7.16^{\star \star}$ \\
\hline \multirow[t]{2}{*}{15} & Yakut & $22.83 \pm 5.82^{\star \star}$ & $21.97 \pm 5.54^{* *}$ \\
\hline & Russian & $28.50 \pm 6.71^{\star \star}$ & $27.54 \pm 7.68^{\star *}$ \\
\hline
\end{tabular}

According to the centile tables of 10 and 12 years old, Russian boys have the dynamometry of the right hand and at 11 and 13 years old the dynamometry of the left hand is in the 90-centile corridor. At the age of 12, for Yakut boys, the dynamometry of the left hand is in 
the 90-centile corridor, and for Russian boys in the 97centile corridor. Russian girls 8, 9, 12, 13, 14 and 15 years old, the dynamometry of the right hand is in the 90-centile corridor. The dynamometry of the left hand at $8,9,11,13,14$ and 15 years is located in the 90 the 97 centile corridor, at 12 years old in the 90 centile corridor. centile corridor. At 10 years old, the dynamometry of the left hand of Yakut and Russian girls is located in.

\section{CONCLUSIONS}

The state of health of children is one of the indicators of the quality of the environment, social wellbeing and the level of health of the country. The physical development of children and adolescents is one of the informative indicators of the health status of the population.

According to anthropometry, modern schoolchildren have average physical development. The body length indicators of boys and girls aged from 8 to 10 years are the same. According to our data 11, 12-year-old girls are higher than boys of the same age, and from the age of 14 the body length of boys exceeds the body length of girls. Body weight indicators do not have reliable differences in gender, however, at the age of 13, the body weight of Russian boys is significantly more than the body weight of Yakut boys $(\mathrm{p}<0.05)$ and girls at the same age weigh more Yakut boys. Russian girls have higher power opportunities in all age categories than Yakut girls. Boys of Russian nationality, except for 14 years, have higher dynamometry values than boys of Yakut nationality. The power capabilities of Russian boys of prepubertal age belong to high values of physical development. In girls of Russian nationality, the level of dynamometry in all age categories belongs to the 90-centile corridor, which indicates high physical development. For girls of Yakut nationality, only at the age of 10 and 12, power capabilities are higher than average values. Thus, in children of Russian nationality living in the Republic of Sakha (Yakutia), functional indicators (hand dynamometry) exceed average values. The revealed features of the physical status of children and adolescents clearly require targeted observation by the medical staff of the school and clinic, which includes an assessment of the level of morphological maturity and physical development of each student.

\section{REFERENCES}

[1] L.D. Izotova, Kazan Med. J. 96(6) (2015) 10151021.

[2] R.R. Kildiyarova, Current Pediatr. 16(5) (2017) 431-437. Retrieved from: https://doi.org/10.15690/vsp.v16i5.1808
[3] V.R. Kuchma, N.A. Skoblin, Iss. of modern pediatr. 7(1) (2008) 26-28.

[4] V.R. Kuchma, N.A. Skoblina, D.S. Nadezdin, Pediatr. 98(5) (2019) 196-201. DOI: 10.24110/0031-403X-2019-98-5-197-201

[5] R.A. Abbot, P.S. Davies, Eur. J. Clin. Nutr. 58 (2004) 258-291.

[6] Y. Wang, C. Monteiro, B.M. Popkin, Am. J. Clin. Nutr. 75(6) (2002) 971-977. Retrieved from: https://doi.org/10.1093/ajen/75.6.971

[7] O.Yu. Milushkina, Bull. of the Rus. State Med. Univ. 3 (2013) 68-71.

[8] E.V. Anufrieva, L.Yu. Neupokoeva, O.P. Kovtun, Rus. Pediatr. J. 1(2) (2020) 5-9. Retrieved from: https://doi.org/10.15690/rpj.v1i2.2087

[9] O.Yu. Milushkina, D.M. Fedotov, N.A. Bokareva, Bull. of the Rus. State Med. Univ. 1 (2013) 62-65.

[10] I.M. Vorontsov, A.V. Mazurin, Propaedeutics of childhood diseases, Foliant, St. Petersburg, 2010.

[11] WHO child growth standards: methods and development, World Health Organizat., Geneva, $2006 . \quad$ Retrieved from: http://www.who.int/childgrowth/standards/technica 1_report/en

[12] L.S. Namazova-Baranova, K.A. Yeletskaya, E.V. Kaytukova, S.G. Makarova, Pediatr. pharmacol. 15(4) (2018) 333-342. Retrieved from: https://doi.org/10.15690/pf.v15i4.1948

[13] V.A. Peterkova, O.V. Vasyukova, Probl. of endocrinol. 61(2) (2015) 39-44. Retrieved from: https://doi.org/10.14341/probl201561239-44

[14] Yu.A. Yampolskaya, N.A. Skoblina, N.A. Bokareva, Bull. of Anthropol. 20 (2011) 63-70.

[15] N.N. Sukhanova, Rus. Pediatric J. 2 (1999) 6-41. 
[1] [9] A. Pnueli, In transition from global to modular temporal reasoning about programs, in: K.R. Apt (Ed.), Logics and Models of Concurrent Systems, Springer, Berlin, Heidelberg, 1984, pp. 123-144. DOI: https://doi.org/10.1007/978-3-642-82453-1_5

[2] [10] B. Meyer, Applying "Design by Contract", Computer 25(10) (1992) 40-51. DOI: https://doi.org/10.1109/2.161279

[3] [11] S. Bensalem, M. Bogza, A. Legay, T.H. Nguyen, J. Sifakis, R. Yan, Incremental component-based construction and verification using invariants, in: Proceedings of the Conference on Formal Methods in Computer Aided Design (FMCAD), IEEE Press, Piscataway, NJ, 2010, pp. 257-256.

[4] [12] H. Barringer, C.S. Pasareanu, D. Giannakopolou, Proof rules for automated compositional verification through learning, in Proc. of the 2nd International Workshop on Specification and Verification of Component Based Systems, 2003.

[5] [13] M.G. Bobaru, C.S. Pasareanu, D. Giannakopoulou, Automated assume-guarantee reasoning by abstraction refinement, in: A. Gupta, S. Malik (Eds.), Proceedings of the Computer Aided Verification, Springer, Berlin, Heidelberg, 2008, pp. 135-148. DOI: https://doi.org/10.1007/978-3-540-70545-1_14 